\title{
A Novel Technique of Biological Osteosynthesis in a Bicondylar Tibial Fracture
}

\author{
Yogesh Sharad Salphale*, Nitin Kimmatkar, Vikrant G. Salphale, Wasudeo Gadegone, Rabi Mohapatra, Anuradha Y. Salphale, \\ Jenny Garg, Ketaki Mohite \\ Shushrusha Multispecialty Hospital, Lane Opp. Z.P, Chandrapur, Maharashtra, India
}

Correspondence to: Yogesh Sharad Salphale, Shushrusha Multispecialty Hospital, Lane Opp. Z.P, Chandrapur 442401 (India)

Received date: January 03, 2022; Accepted date: January 14, 2022; Published date: January 21, 2022

Citation: Salphale YS, Kimmatkar N, Salphale VG et al. (2022) A Novel Technique of Biological Osteosynthesis in a Bicondylar Tibial Fracture. J Med Res Surg 3(1): pp. 4-9. doi: 10.52916/jmrs224067

Copyright: (C2022 Salphale YS, et al. This is an open-access article distributed under the terms of the Creative Commons Attribution License; which permits unrestricted use; distribution and reproduction in any medium; provided the original author and source are credited.

\section{ABSTRACT}

Purpose: To evaluate the biological treatment outcomes for tibial plateau fractures.

Methods: 8 men and 4 women aged 21 to 54 (mean, 36) years with closed tibial plateau fractures were enrolled for the study. According to the Schatzker classification, patients were classified into type I $(n=1)$, type II ( $n=2)$, type IV $(n=4)$, and type $V(n=5)$. After closed reduction the fracture was fixed with two to three $6.5 \mathrm{~mm}$ cannulated cancellous screws and crossed $\mathrm{K}$ wires.The functional outcome was evaluated using the Rasmussen score. A total score of 28 to 36 was considered as excellent, 20 to 27 as good, and less than 10 as poor.

Results: Patients were followed up for a mean of 2.2 (range, 1-3.4) years. All the fracture united radiographically after a mean of 3 (range, 2.3-4.3) months. Respectively in Schatzker types-I, II, IV, and V fractures, outcomes were excellent in 1, 2, 3, and 3 patients, It was good in $0,0,1$, and 1 patients, fair in $0,0,0$, and 1 patient, and poor in $0,0,0$, and 0 patients. Outcome was satisfactory (good-to-excellent) in $85 \%, 86 \%, 100 \%$, and $80 \%$ of the respective fracture types of patients. The mean Rasmussen score was 26.7 for all patients; it was $\mathbf{2 7 . 7}$ for type I, 26.5 for type II, 28.9 for type IV, and $\mathbf{2 4 . 4}$ for type V fractures. No infection, wound dehiscence or hardware issues were noted.

Conclusion: This technique offers improved fracture healing without any risk of soft tissue complications, minimising the hospital stay and expenditure.

\section{Keywords:}

Proximal tibia fracture, Cannulated cancellous screws, Crossed $\mathrm{K}$ wires, Tibial plateau fractures, Minimally invasive surgery

\section{Introduction}

The fractures of the tibial plateau pose a challenge to the surgeons managing them for their varied presentation. From innocuous soft tissue injury to complex fracture pattern associated with extensive soft tissue injuries, to find the right balance needs a good clinical judgement.

Though there are a variety of conservative and surgical procedures designed to manage the same, there is still no consensus in the management. The manuscript evaluates the various options available stressing on the biological aspect. The treatment outcomes for tibial plateau fractures managed by this method is economical, soft tissue friendly and can be carried out in places with limited surgical setup. The economic advantages of this procedure outweighs the costly surgical implants,giving a reasonably good outcome.

\section{Material and Methods}

Between September 2018 and January 2021, 8 men and 4 women aged 21 to 54 (mean, 36 years ) years underwent closed reduction and percutaneous cannulated cancellous screws fixation along with crossed $\mathrm{K}$ wires for closed tibial plateau fractures with $<5 \mathrm{~mm}$ depression. 7 of them involved the right side. The causes of injury included high-velocity road traffic accident $(n=6)$, direct hit by car on the lateral side of the knee $(n=1)$, and fall from a height $(n=5)$. According to the Schatzker classification, the patients were classified into type I (lateral fracture) $(n=1)$, type II (lateral fracture with depression) $(n=2)$, type IV (any medial fracture) $(n=4)$, and type $V$ (bicondylar fracture) $(n=5)$. Associated injuries included fractures of the fibula $(n=1)$, tibial spine $(n=1)$. The inclusion criteria in our studies were young adults above 18 years of age, with closed extra-articular and intra-articular fractures of proximal tibia and compound proximal tibia fractures up to Grade IIIA without any infection. Patients with compound fractures not having adequate soft tissue coverage,with associated neurovascular/ head injury compartment syndrome, were excluded. Similarly patients with type III (lateral depression), type VI (fracture extending to the metaphysis) and extensive communition with more than $5 \mathrm{~mm}$ depression were excluded.

This study was approved by the ethics committee of our hospital. Informed consent was obtained from each patient after explaining them of the procedure.

Anteroposterior and lateral radiographs of the knee joint were obtained. CT scan was resorted in two cases where we suspected a posteromedial fracture and an articular depression more than $5 \mathrm{~mm}$.

The patients were placed in an above knee posterior plaster slab.When we suspected the soft tissue insult due to initial injury and a possibility of surgical delay, the limb was placed 
in lower tibial skeletal traction. A predesigned proforma was used to record patient information, injury mechanism, damage pattern (based on Schatzker classification), distal neurovascular status, and concomitant injuries. Patients were operated on as soon as they were medically fit and the soft tissue insult receded by the appearance of wrinkle sign. Surgery was delayed for 7 to 12 days in 2 patients with blisters or persistent tense swelling. Excluding these 2 patients, the mean delay in surgery was 2 (range, 1-8) days.

All patients were given IV antibiotic injection Cefotaxime 1 gm plus IV injection Amikacin 500 mg 12 hourly for three days. The patients were operated in supine position under spinal anaesthesia and $\mathrm{C}$ arm guidance. Fracture reduction was carried out by longitudinal traction. The Intra articular split was reduced by using either a tibial distractor, a Schanz pin, temporary fixation with $\mathrm{K}$ - wires or a pointed reduction forceps. We resorted to two $\mathrm{K}$ wires, after the reduction was found satisfactory. In three cases we had to use give a small incision to manoeuvre the intra
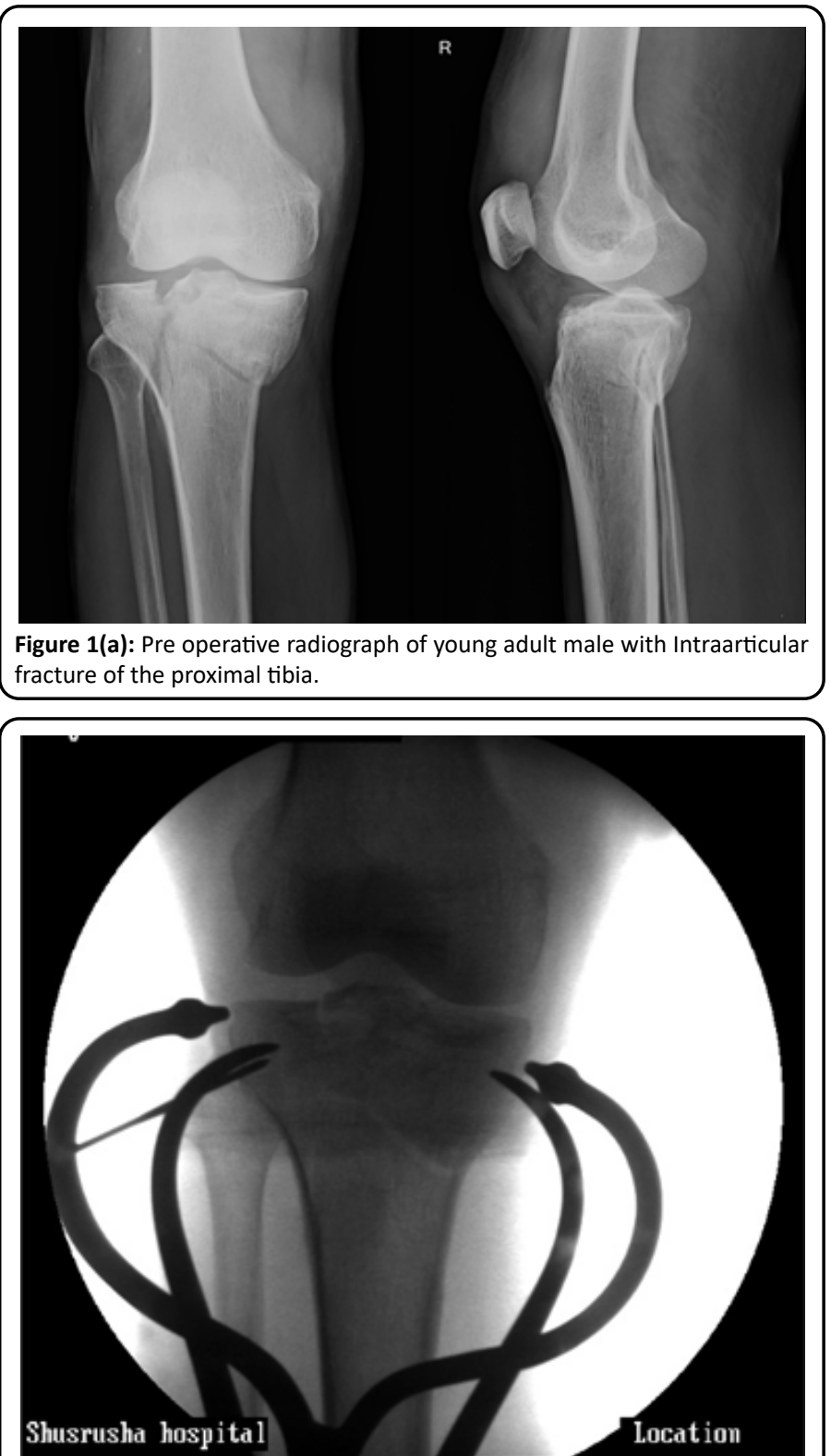

Figure 1(b): Intraoperative $C$ arm picture of the reduced fracture with reduction clamps in position. articular depressed fragments and to get the articular alignment. Guide wires were passed parallel to the tibial articular surface and after ascertaining their position under C-arm in both the planes, two to three cannulated cancellous screws with or without the washer was used. The temporary transverse $K$ wires were removed once the screws were inserted. The direction and the number of screws $(\geq 2)$ used were based on the fracture pattern and the orientation (Figure $1(\mathrm{a}-\mathrm{g})$ ).
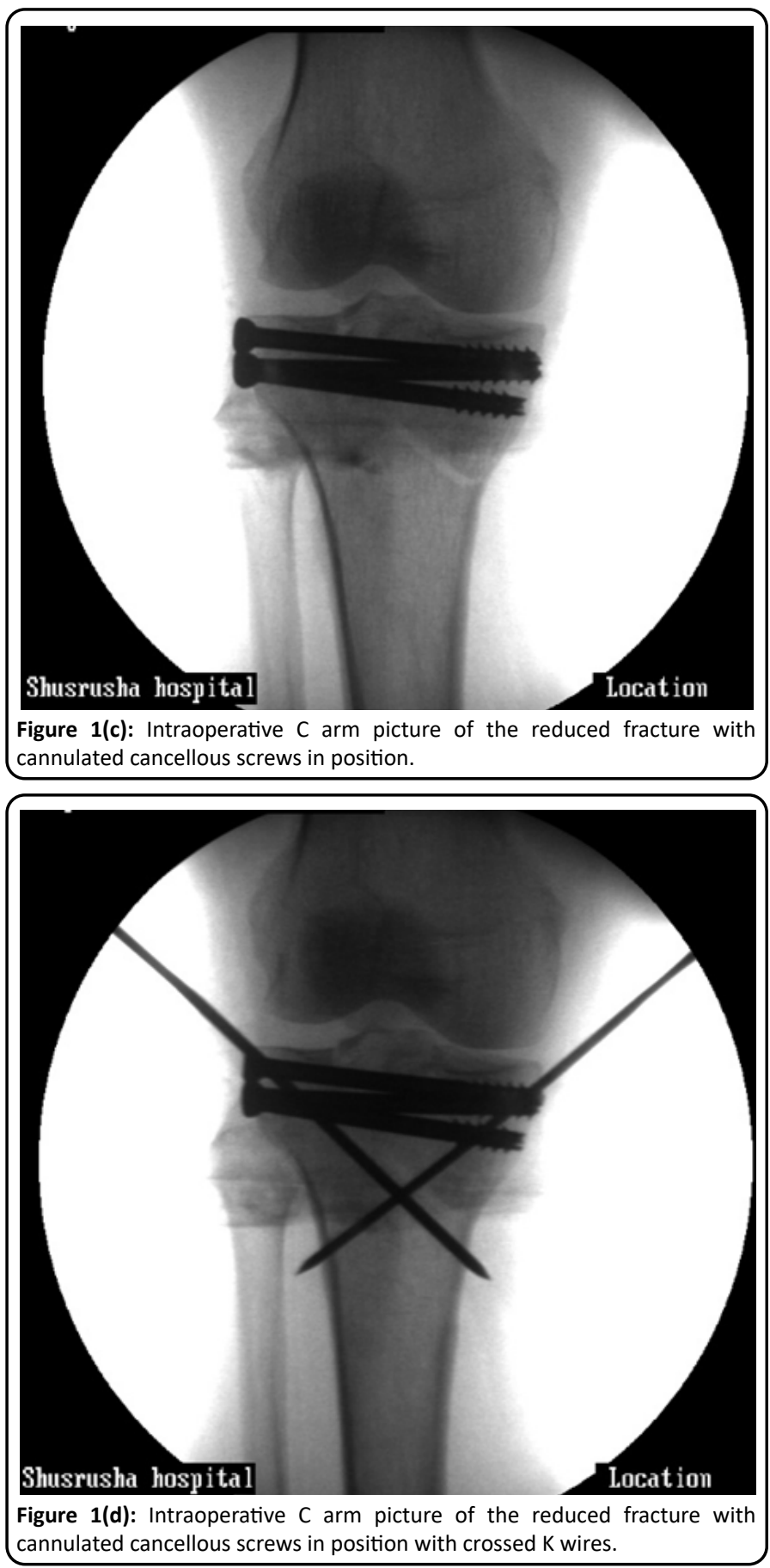

The metadiaphyesal aspect of the fracture was reduced with either a varus/valgus gentle force. It was fixed with two $2.5 \mathrm{~mm}$ $\mathrm{K}$ wires passed obliquely from the medial and lateral direction to capture the opposite metaphysis. It was checked under C arm in AP and lateral view.

The $K$ wires were left outside the skin proximally to aid in removal after a period of five weeks (Figure 2 (a-c)). The 


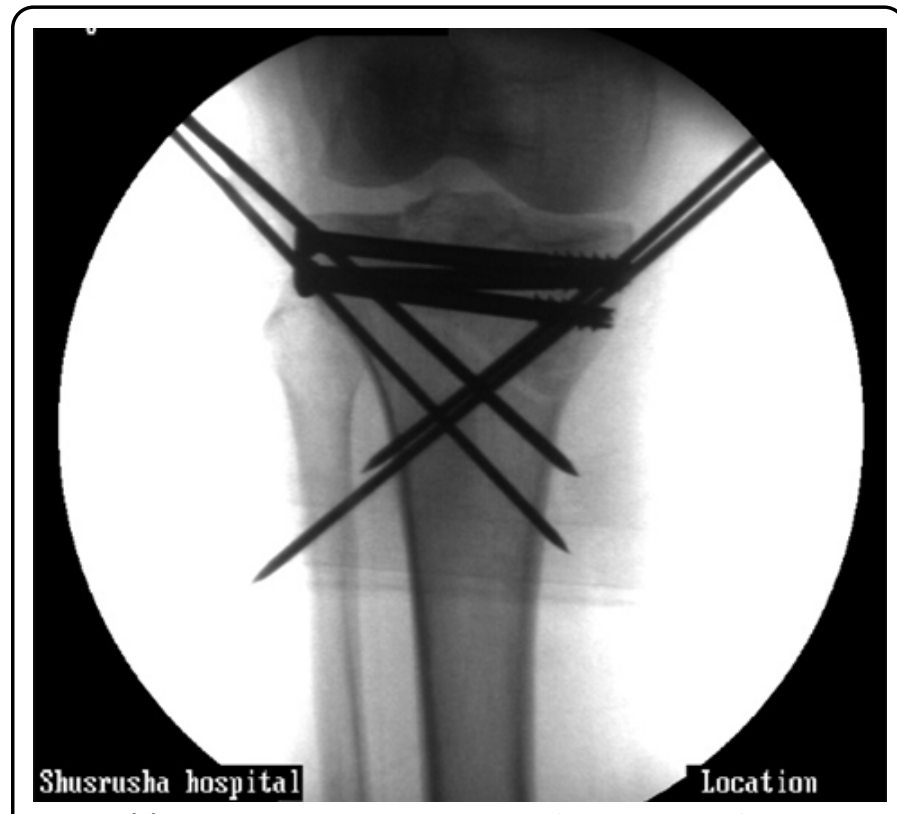

Figure 1(e): Intraoperative $C$ arm picture of the reduced fracture with cannulated cancellous screws in position with multiple crossed $\mathrm{K}$ wires holding the fracture reduced (The image on the withdrawn, proud $\mathrm{K}$ wire,laterally could not be procured).

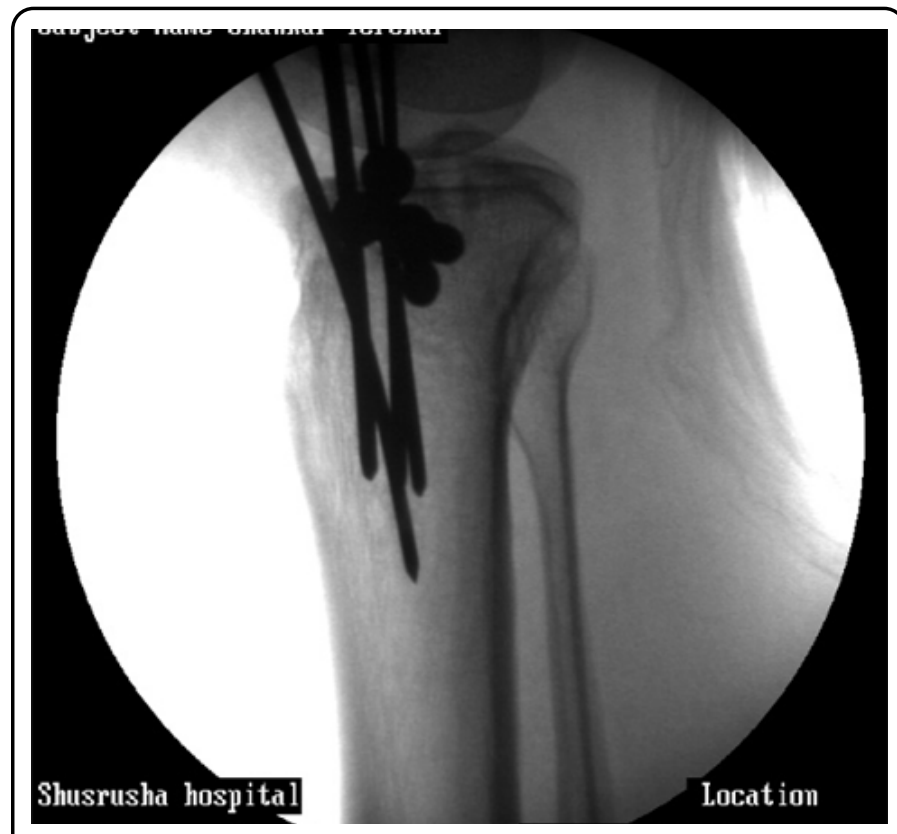

Figure 1(f): Intraoperative lateral $C$ arm picture of the reduced fracture with cannulated cancellous screws in position with multiple crossed $\mathrm{K}$ wires holding the fracture reduced.

strength of the entire construct was assessed postoperatively under the $\mathrm{C}$ arm.

In two cases we had to use a screw from medial to lateral direction along with the lateral to medial screws and the crossed $\mathrm{K}$ wires (Fig 3(a-d)).

The wound was closed and a cylinder cast with 10 degrees of flexion was applied. The patient was discharged after seventy two hours and was advised to follow up after five weeks.

After five weeks, the cast was removed, and the knee joint was checked for discomfort, swelling, and instability. For the next one week, gentle knee bending and extension exercises were recommended, as well as non-weight-bearing crutch walking.

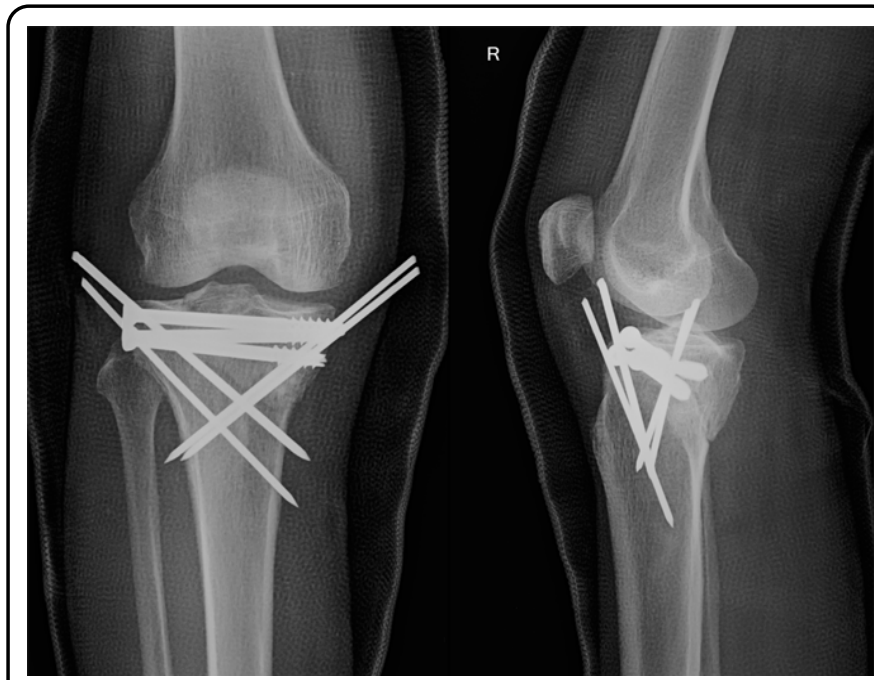

Figure 1(g): X-ray with the cast at 5 weeks post op showing a well reduced fracture with cannulated cancellous screws in position with multiple crossed K wires.

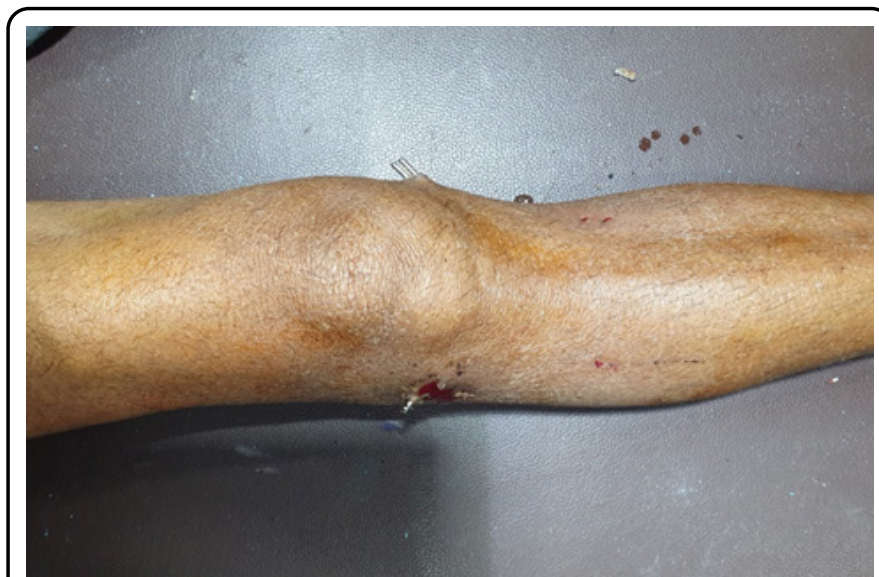

Figure 2(a): Showing the K wires medially and laterally after removal of the cast.

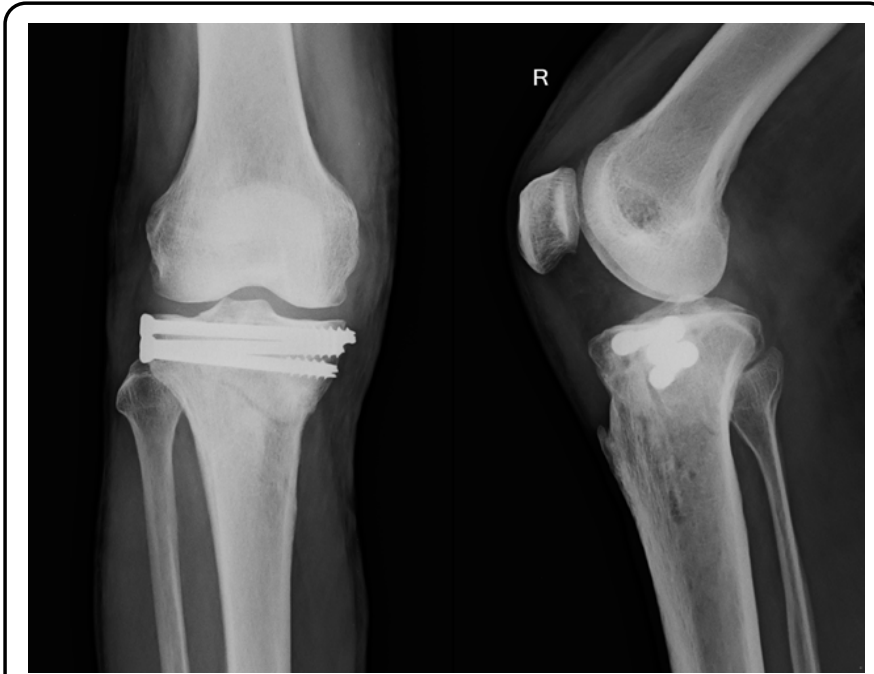

Figure 2(b): X-ray at 13 mths post op showing a well reduced fracture with cannulated cancellous screws in position with multiple crossed $\mathrm{K}$ wires.

The rehabilitation protocol for all patients included Isometric quadriceps workouts, ankle pumps, and toe movements. Weeks 6 and 12 allowed partial and full weight bearing, respectively. Radiological evaluation of fracture union was observed by serial 

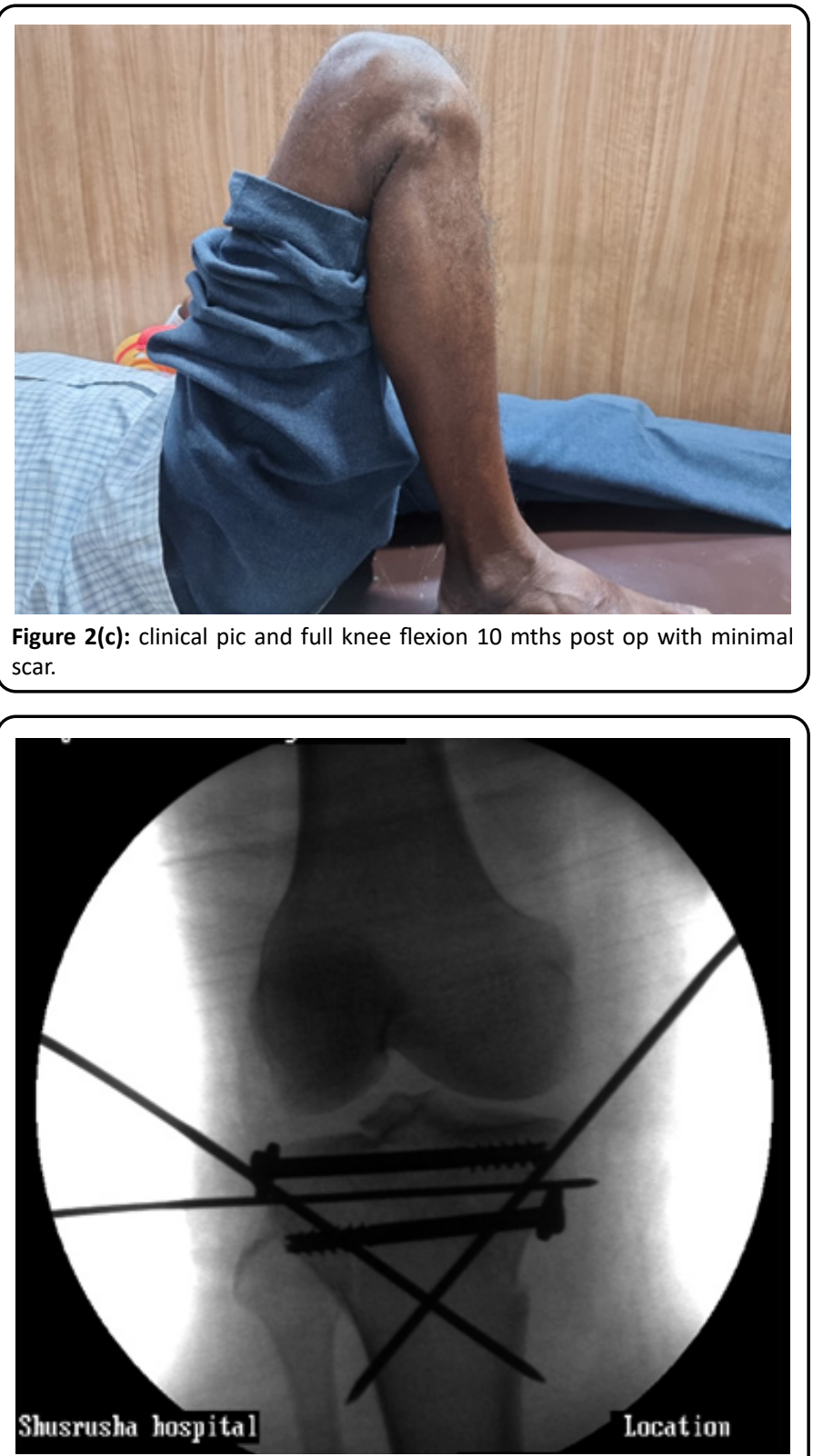

Figure 3(a): Pre operative radiograph of young adult female with Intraarticular fracture of the proximal tibia.

X-rays. Patients were followed up on at six and twelve months, as well as once a year after that. The minimum follow-up period was one year and maximum follow up period was 26 months. The functional outcome (pain, walking capacity, extension lag, range of motion, and stability) was assessed during the final follow-up using the Rasmussen score [1-6].

\section{Discussion}

Tibial plateau fractures are prevalent in the elderly, and axial loading is virtually always the major injury force. Rotational and angular forces are frequently implicated in such injuries. In an osteoporotic person, a simple act like stepping off a curb can result in a heavily comminuted proximal tibia fracture.

In these fractures, the articular surface is usually displaced and impacted down into the softer cancellous bone of the proximal tibia. The preservation of the knee's complex ligamentous supporting systems, as well as the restoration of a sufficient joint surface, are important therapeutic considerations.

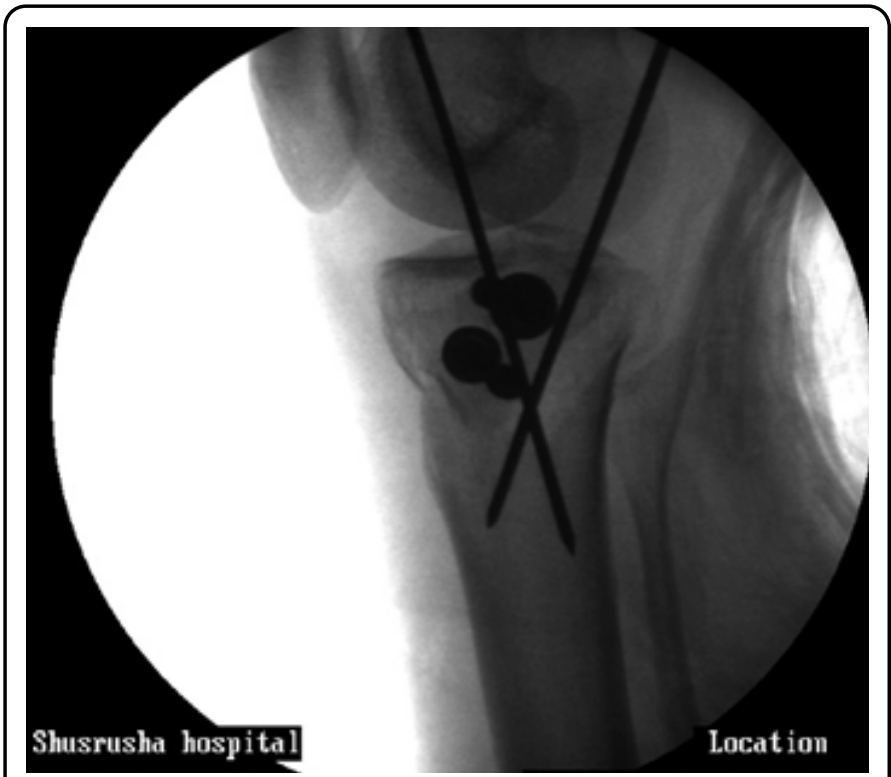

Figure 3(b): Post operative $C$ arm images of young adult female with Intraarticular fracture of the proximal tibia
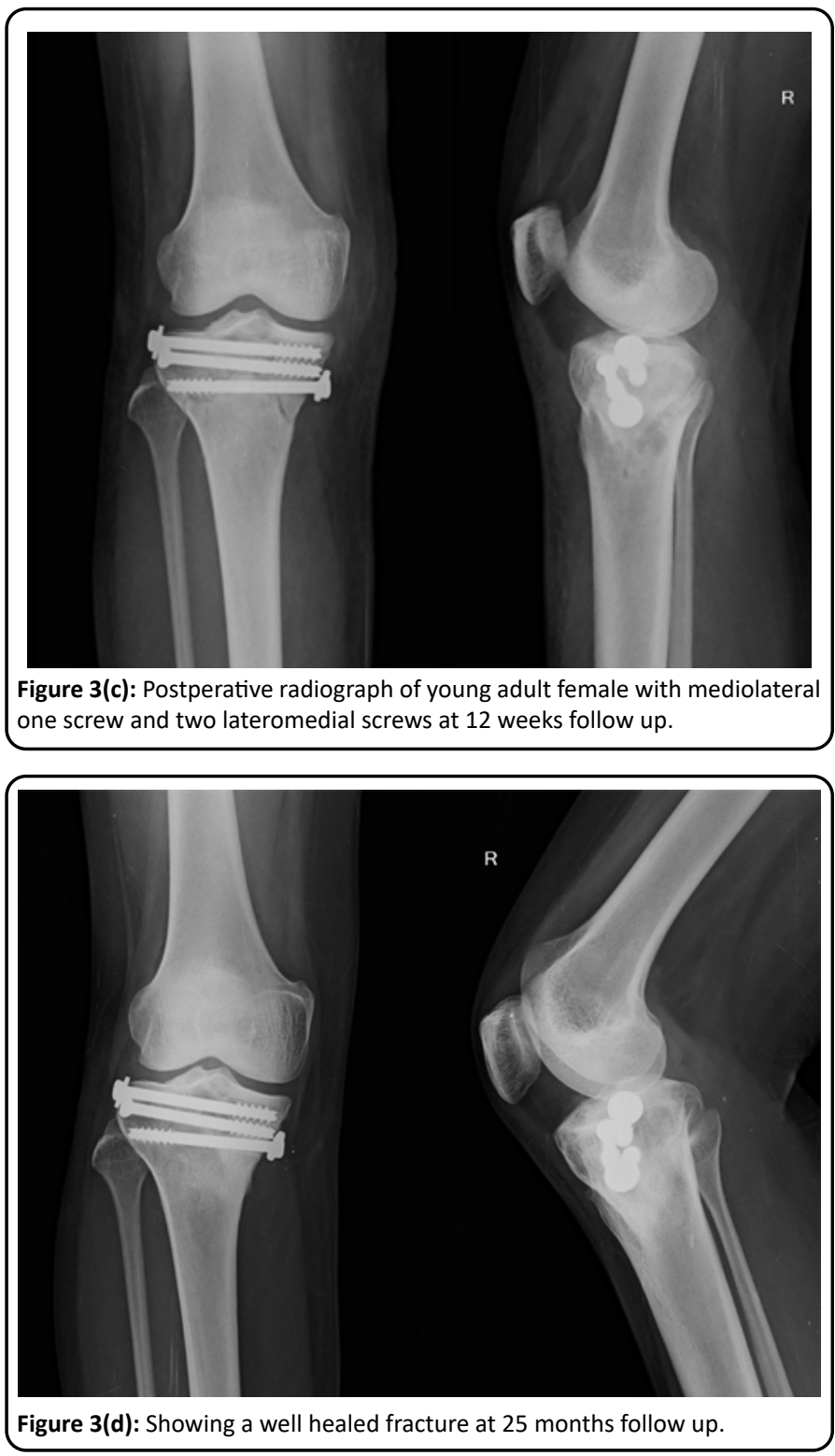

Page 7 of 9 
The ability to minimise and stabilise the fracture with minimal or no soft tissue dissection in an already compromised soft tissue environment is essential in fracture of the proximal tibia.

The Illizarov apparatus have been tried with good results. When compared to typical external fixators, the ring construct with tensioned wires provides higher mechanical stability and superior metadiaphyseal purchase and support. In soft cancellous bone, tensioned wires give good grip. They act as a scaffold in buttressing the subchondral bone preventing collapse, restore the intrinsic stability of the fracture site with a bridging device, and allow the patient to transfer his or her weight through this flexible scaffold to the distal diaphysis, bypassing the comminuted area and permitting early joint movement and weight bearing while maintaining reduction [7].

We agree that the mini-open reduction, bone graft, minimal internal fixation, and a limited period of knee immobilisation as advocated by various authors [7-9] all make the treatment more technically straightforward without sacrificing the end result.

Traditional open reduction and internal fixation with two plates has yielded mixed outcomes, as significant soft-tissue stripping can cause issues and have a high complication rate [10-12] which overshadows the benefits of correct articular surface reduction and early knee joint mobility.

There have been others who advocate for the use of lateral locking plates $[8,13]$. Gosling $T$ et al. concluded that unilateral plating with locking head screws is a viable treatment option for bicondylar tibial plateau fractures in a study of $63 \mathrm{AO} / \mathrm{ASIF}$ C-type tibial plateau fractures [14]. The lateral locking device in the proximal tibia fracture provides stiff construct stability and can withstand normal physiological loads [15].

Bicolumn plating for bicondylar tibial plateau fractures [1618] also benefits from minimally invasive plate osteosynthesis. Bicolumn plating is usually done with two distinct incisions, which can cause considerable damage to soft tissues, periosteum, and sometimes the viability of the skin and soft tissues in between the incisions, result in postoperative problems $[19,20]$. The application of minimally invasive plate osteosynthesis is limited because it is extremely demanding and technically tough in patients with complex proximal tibial fractures and in fractures requiring bone grafting, which requires appropriate exposure [21]. Aside from this, this approach can be used to treat proximal tibial fractures and provide good functional and radiological results with little soft tissue problems.

A minimally invasive reconstruction technique of lateral tibial plateau fractures using a three-screw jail technique in the prevention of screw cut-outs through the cancellous bone have also been proposed with seemingly similar biomechanical properties [22]. A standard fixation with one additional support screw at the distal end of the fracture at $30^{\circ}$ proximal inclination in addition to the conventional $6.5 \mathrm{~mm}$ cancellous screw have also been proposed for the management of the lateral tibial fractures [23].

The cannulated cancellous screws aid in the approximation of the intra articular fracture whereas the two crossed $\mathrm{K}$ wires, in our series, helps in prevention of the subsidence of the medial or lateral tibial plateau. The two $\mathrm{K}$ wires on either side, span out to engage the opposite diaphyseal fragment and afford the stability till eventual union. The collapse of the fracture,if present is quite controlled. The small incisions and the minimal surgical footprint does not complicate the future knee replacement, should the need arises.

To prevent varus collapse a temporary external fixator or a small medial plate on the medial side have been suggested [24]. In the technique which we propose, the crossed $\mathrm{K}$ wires which are passed from the proximal-medial to distal- lateral direction. A period of the casting for a period of four to five weeks allows the fracture to heal. Minor adjustments (varus-valgus) can be easily carried before the cast is applied. Hence the role of a cast in the management and as an adjunct can never be ignored. The injured knee should not be in the cast beyond six weeks but early mobilization with a hinged brace should be considered, which allows joint mobility and provides some coronal support. An above knee cast does not compromise the eventual functional result. None of our patients had any valgus or varus deformity.

Soft tissue injuries have a variety of treatment options. Because conservative care of $\mathrm{MCL}$ injuries is generally chosen, most surgeons do not currently encourage diagnostic or therapeutic approaches for an associated MCL injury. In addition, the medial ligament does not cause long-term problems, and residual laxity is usually caused by bone depression rather than collateral ligament laxity. Moore et al. [25] used stress radiographs to look for varus or valgus laxity in 208 people who had unicondylar tibial plateau fractures three years after the event. When comparing the injured and healthy knees, they detected no increased laxity in the injured knee, indicating continued collateral ligament injury.

We agree that the reduction and fixation of posterolateral and posteromedial fragments are not possible with our proposed surgical techniques. To do so, they must be reduced and fixed using specialised posterolateral or posteromedial techniques that allow for appropriate plate/screw insertion and reduction [26].

Ligament repair was not done on any of our patients other than to reduce and stabilise a lateral plateau fracture, and the collateral ligament injury were treated with a simple postoperative brace or immobiliser. In our small series, the limb axis was successfully maintained, and no mediolateral instability was observed in our patients.

Because the proximal tibia is commonly crushed and bone stock is lost, the vacuum left in the tibial metaphysis, when the articular surface is lifted frequently necessitates a graft to both fill the void and reinforce the joint fragments. In our technique the length, alignment and articular reconstruction was carefully assessed and addressed. The crossed $\mathrm{K}$ wires and a period of immobilization in the above knee cast did not necessitate the need of bone graft or any substitute.

\section{Conclusion}

We conclude that closed reduction and internal fixation with cannulated cancellous screws and crossed $\mathrm{K}$ wires gives excellent results for displaced fractures belonging to Schatzker types-I, II, IV and V fractures In a developing country and in situations where the setup is limited, this aseptic,minimally invasive operative technique, costing under less than 15 US\$ can equally give good results compared to the extensive surgery 
which may jeopardize the soft tissue and cause post operative complications.

A motivated patient, good anatomical reconstruction of the articular surface, stable fixation, early ROM physiotherapy after removal of plaster cast helps to achieve knee arc of motion in the functional degrees.

Needless to mention, an above knee cast for a period of five weeks does not compromise the eventual function of the knee.

Though this is a small series, we feel a larger series shall definitely help in establishing this method in the management of the proximal tibia fracture.

\section{References}

1. Hohl M (1993) Articular fractures of the proximal tibial. In: Evarts CM, editor. Surgery of the musculoskeletal system. New York: Churchill-Livingstone 1993: pp. 3471-3497.

2. Joseph Schatzker, Marvin Tile (1987) The rationale of operative fracture care. Berlin: Springer-Verlag, pp. 279-295.

3. Stevens DG, Beharry R, McKee MD, et al. (2001) The longterm functional outcome of operatively treated tibial plateau fractures. J Orthop Trauma 15(5): pp. 312-320.

4. Sangwan SS, Siwach RC, Singh R, et al. (2002) Minimal invasive osteosynthesis: a biological approach in treatment of tibial plateau fractures. Indian J Orthop 36(4): pp. 246-250.

5. Shete K, Sancheti P, Kamdar R (2006) Role of Esmarch bandage and percuteneous cannulated cancellous screws in tibial condylar fracture. Indian J Orthop 40(3): pp. 173-176.

6. Rasmussen PS (1973) Tibial condylar fractures. Impairment of knee joint stability as an indication for surgical treatment. J Bone Joint Surg Am 55(7): pp. 1331-1350.

7. Ali AM, Burton M, Hashmi M (2003) Outcome of complex fractures of the tibial plateau treated with a beam-loading ring fixation system. J Bone Joint Surg Br 85(5): pp. 691-699.

8. Wu D, Reng G, Shrivastava A, et al. (2015) A useful surgical strategy for proximal tibial fractures (AO/OTA type 41-C) with diaphyseal involvement. Int J Clin Exp Med 8(8): pp. 1345513463.

9. Sament R, Mayanger JC, Tripathy SK, et al. (2012) Closed reduction and percutaneous screw fixation for tibial plateau fractures. J Orthop Surg (Hong Kong) 20(1): pp. 37-41.

10. Schatzker J, McBroom R, Bruce D (1979) The tibial plateau fracture. The Toronto experience 1968-1975. Clin Orthop Relat Res 138: pp. 94-104.

11. Stokel EA, Sadasivan KK (1991) Tibial plateau fractures: standardized evaluation of operative results. Orthop 14(3): pp. 263-270.

12. Young MJ, Barrack RL (1994) Complications of internal fixation of tibial plateau fractures. Orthop Rev 23(2): pp. 149154.
13. Spagnolo R, Pace F (2012) Management of the Schatzker VI fractures with lateral locked screw plating. Musculoskelet Surg. 2012;96: pp. 75-80.

14. Gosling T, Schandelmaier P, Muller M, et al. (2005) Single lateral locked screw plating of bicondylar tibial plateau fractures. Clin Orthop Relat Res 439: pp. 207-214.

15. Lindeque B, Baldini T (2010) Biomechanical comparison of three different lateral tibia locking plates. Orthop 33(1): pp. 1821.

16. Krettek C, Müller M, Miclau T (2001) Evolution of minimally invasive plate osteosynthesis (MIPO) in the femur. Injury 32(S3): pp. SC14-SC23.

17. Sirbu PD, Petreus T, Asaftei R, et al. (2011) Minimally invasive plate osteosynthesis in long bone fractures-BiomechanicsDesign-Clinical Results; Biomechanics in Applications edited by Václav Klika, pp. 101-124.

18. Oh CW, Oh JK, Kyung HS, et al. (2006) Double plating of unstable proximal tibial fractures using minimally invasive percutaneous osteosynthesis technique. Acta Orthop 77(3): pp. 524-530.

19. Chen ZY (2008) A comparison of results between minimally invasive percutaneous plate osteosynthesis and interlocking intramedullary nail for treatment of tibial fractures. Chin J Prim Med Pharm 15: pp. 1603-1604.

20. Chen H, Du GZ, Li JJ (2005) A comparative study of treatment of tibial fractures with minimally invasive percutaneous plates and with interlocking intramedullary nails Guangzhou Med J 36(2): pp. 69-71.

21. Jiang YB (2011) A retrospective comparative study of tibial fractures treated by closed reduction with minimally invasive percutaneous plates and with interlocking intramedullary nails. China Foreign Med Treat 30: p. 98.

22. Weimann $A$, Heinkele $T$, Herbort $M$, et al. Schliemann B, Petersen W, Raschke MJ, (2013) Minimally invasive reconstruction of lateral tibial plateau fractures using the jail technique: a biomechanical study. BMC Musculoskelet Disord 14(1): p. 120.

23. Moran E, Zderic I, Klos K, et al. (2017) Reconstruction of the lateral tibia plateau fracture with a third triangular support screw: A biomechanical study. J Orthop Translat 11: pp. 30-38.

24. Delamarter R, Hohl M (1989) The cast brace and tibial plateau fractures. Clin Orthop Relat Res 242: pp. 26-31.

25. Moore TM, Meyers MH, Harvey JP Jr. (1976) Collateral ligament laxity of the knee. Long-term comparison between plateau fractures and normal. J Bone Joint Surg Am 58(5): pp. 594-598.

26. Prat-Fabregat S, Camacho-Carrasco P (2017) Treatment strategy for tibial plateau fractures: an update. EFORT Open Rev 1(5): pp. 225-232. 